archaeological material from Unai, Minas Gerais, Brasil. Trans. R. Soc. Trop. Med. Hyg., 74: 798-800, 1980.

2. FERREIRA, L.F. et alii. The finding of helminth eggs in a Brazilian mummy. Trans. R. Soc. Trop. Med. Hyg., 77 (1): 65-7, 1983.

3. FRY, G.F. \& MOORE, J.G. Enterobius vermicularis 10.000 years-old human infection. Science, 166:1620, 1969.

4. PATRUCCO R. et alii. Parasitological studies of cropolites of Pre-Hispanic Peruvian population. Curr. Anthropol., 24 (3) Jun., 1983.

5. ZIMMERMAN, M.R. \& MORILLA, R.E. Enterobiasis in pre Columbian America. Paleopathol. Newsl., (42) Jun., 1983.

\title{
A competição biológica como método alternativo para o controle dos transmissores da esquistossomose.
}

Frederico Simões Barbosa ${ }^{*}$

Trabalhos que vêm sendo desenvolvidos nos estados de Pernambuco e da Paraíba, há alguns anos, sobre o controle biológico dos moluscos transmissores da esquistossomose, revelaram que Biomphalaria straminea tem comprovada capacidade competitiva sobre $B$. glabrata.

Trabalhando com uma cepa de $B$. straminea resistente a infecção por Schistosoma mansoni os pesquisadores do Centro de Pesquisas Aggeu Magalhães, em Recife, demonstraram que, em ambiente seminatural criado no laboratório, $B$. straminea tem a capacidade de deslocar totalmente a população-alvo de $B$. glabrata dentro do período de cerca de dois anos. O mesmo fenômeno ocorre com outra cepa de $B$. straminea semi-resistente a infecção por $S$. mansoni, nas mesmas condiçðes acima.

Outros aspectos da competição foram estudados em laboratório, ficando demonstrada a superioridade do competidor contra a população-alvo. Assim, B. straminea tem maior capacidade de dispersão, vagilidade e resistência à dessecação que $B$. glabrata $^{1}$.

$O$ experimento de campo vem revelando que o fenômeno ocorre com as mesmas características de deslocamento competitivo entre duas populaçðes. No momento, dois anos
* Escola Nacional de Saúde Pública - FIOCRUZ, Rio de Janeiro e Centro de Pesquisas Aggeu Magalhaes - FIOCRUZ, Recife-PE. 
depois da introdução do competidor em um pequeno vale do município de Alhandra, estado da Paraíba, o competidor ocupa cerca de $2 / 3$ do território antes habitado exclusivamente pela população natural de $B$. glabrata.

Os resultados obtidos abrem uma nova via de investigação sobre métodos alternativos de controle de uma infecção como a esquistossomose, considerada importante problema de saú de pública em algumas regióes do país como o nordeste úmido.

\section{REFERENCIAS BIBLIOGRÁFICAS}

1. BARBOSA, E.S. et alii. Mem. Inst. Oswaldo Cruz, 79 : 163-167, 1984. 